\title{
Editorial: The 20th anniversary of J. Mater. Sci: Materials in Electronics
}

\author{
Arthur Willoughby
}

Published online: 3 August 2010

(C) Springer Science+Business Media, LLC 2010

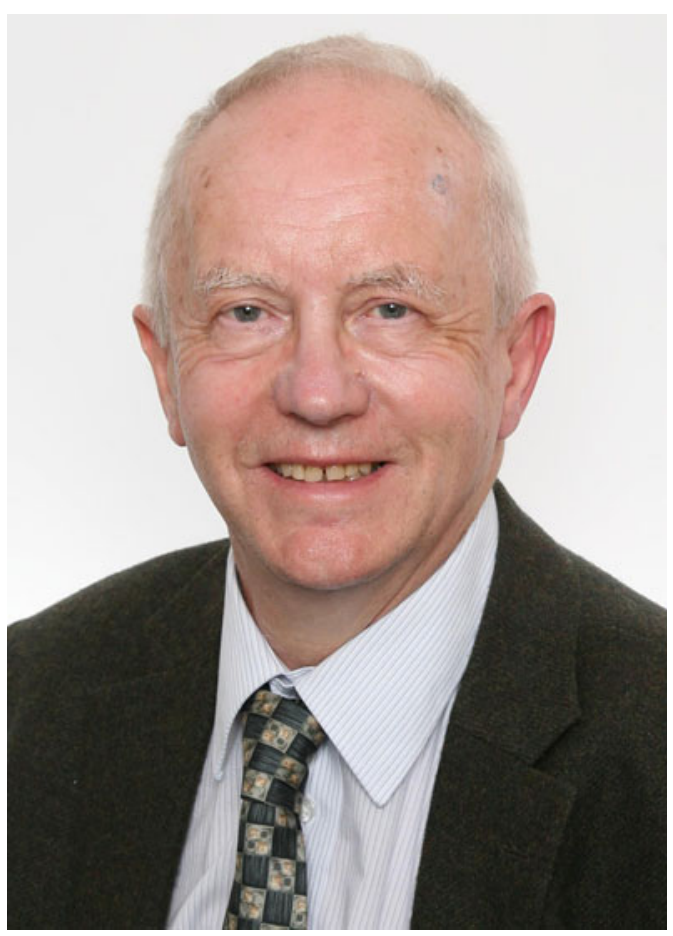

The first issue of J. Mater. Sci: Materials in Electronics was published in May 1990, and so this year represents completion of the first 20 years in the journal's history. As the founding Editor, and Editor-in-Chief for the all of that time, it is a great pleasure to write an Editorial to mark the occasion.

A. Willoughby $(\square)$

Southampton, UK

e-mail: A.F.Willoughby@ soton.ac.uk
As a companion journal to the main Journal of Materials Science, the initiative to launch this journal, together with J. Mater. Sci: Materials in Medicine, was very much thanks to the then Editor of Journal of Materials Science, Professor Bill Bonfield, and the publishing Editor of Chapman and Hall (who published these journals then), Michael Dunn. Their foresight in recognising the strength of these disciplines, and the need to cover them with specialist journals, cannot be emphasised too strongly, and the subsequent success of this journal is witness to their initiative. In the first few years, both Bill Bonfield and Michael Dunn helped to ensure a strong launch to make it successful, and both are recognised here for their invaluable contribution to the journal.

As a new journal in this field, to join the respected and established TMS/IEEE Journal of Electronic Materials, whose Editor, Professor Ted Harman, was always extremely encouraging to me personally, this journal was able to embrace a wide range of aspects of materials in electronics, which has been recognised more recently on the mast-head to cover Optoelectronic Materials and Photonics in addition to the more traditional areas. The first issue contained papers on solar cells, electroceramics, infra-red detector materials, resistors, high-Tc superconductors, optical fibres, magnetic materials, glasses, thin films and phosphors, in only 12 papers! Likewise these first papers included authors from the UK, USA, Japan, France, Italy, Australia, India and Egypt.

All of the papers in this Special Anniversary Issue, 20 years later, have been selected from regularly submitted papers, together with two invited reviews, to represent cutting-edge topics appearing in the normal output of the journal. I have grouped the regular papers into disciplines representing fields of present topical concern: Solar Energy Materials, Optoelectronic Materials and Displays, 
Lead-Free Contacts and Resistors, and Lead-free Electroceramics.

At the beginning of this issue, we are delighted to publish two invited reviews by distinguished authors in their respective fields: Biomimetically inspired Photonic Nanomaterials' by Greg Jason Parker, and 'ZrO2 Thin Films on Si Substrate' by Kuan Yew Cheong'. These reviews, as with other reviews which are a regular feature of our journal, have been edited by my distinguished colleague, Professor Safa Kasap from the University of Saskatchewan, Canada, who is Deputy Editor of the journal, as well as our Reviews Editor. I here record my sincere appreciation of Professor Kasap's tremendous contribution to the journal, since he was appointed in 2001 as Reviews Editor, and in 2006 as Deputy Editor.

The growth in the number of papers submitted to the journal has been very fast, particularly in recent years, and we have been fortunate that Springer have introduced online publication and Editorial management, which has been immensely helpful in our task. In the first year of the journal in 1990, 4 issues were published containing 47 papers and 229 pages, while, in 2009, 12 issues were published containing 188 papers and 1,259 pages, and in addition a Supplement of selected papers from the recent ICOOPMA conference containing 106 papers and 518 pages. In parallel with this, the Editorial Board has determined to publish papers of only the highest quality, and most significant in Impact, with the result that the Impact factor has risen from 0.417 in 1999 to its present level of 1.020 in 2009.

In all of the successive developments of the past 20 years, I pay tribute to the Editorial Board, who have been tremendously supportive, together with referees, and authors. I thank past Publishing Editors of the journal, including Michael Dunn (Chapman and Hall and Thomson), Carl Harris (Kluwer Academic), Greg Franklin (Kluwer and Springer), and our present Publishing Director, Alex Greene (Springer), who has made this issue possible, together with the editorial and production staff. At Southampton University my grateful thanks go to Gill Rood, my editorial assistant, for her unstinting efficiency and loyalty throughout this long period, who has been a major factor in making this journal a success.

In the first Editorial that I wrote for the launch of the journal, I emphasised the need for a journal to extend the coverage of materials science to incorporate their role in the applications themselves. In my view, this issue illustrates the continuing need for such a coverage in the rapidly growing field of materials in electronics, optoelectronics and photonics. 